Editorial

\title{
Inventions and Innovation in Integration of Renewable Energy Systems
}

\author{
Pisitpol Chirapongsananurak ${ }^{1}$ and Surya Santoso ${ }^{2, *}$ \\ 1 Department of Electrical Engineering, Chulalongkorn University, Bangkok 10330, Thailand; \\ pisitpol.c@chula.ac.th \\ 2 Department of Electrical and Computer Engineering, The University of Texas at Austin, Austin, \\ TX 78712, USA \\ * Correspondence: ssantoso@mail.utexas.edu; Tel.: +1-512-471-3371
}

Received: 18 April 2018; Accepted: 11 May 2018; Published: 17 May 2018

Increasing the penetration of renewable energy sources such as photovoltaics, wind turbines, and tidal lagoon power plants raises concerns regarding their impacts on the power systems. Although wind and solar power generation can reduce the peak load demand in distribution circuits, these renewable energy sources may cause voltage and protection issues including voltage regulation, flicker, short-circuit current contribution, and protection coordination. Additional equipment such as capacitor banks, voltage regulators, static var compensators (SVCs), static synchronous compensators (STATCOMs), and energy storage systems may be required to provide enhanced voltage regulation.

The Special Issue "Inventions and Innovation in Integration of Renewable Energy Systems" has provided an insight into the different aspects of renewable energy integration. There are six papers published in this special issue as follows:

The first paper [1] presents a framework for deploying energy storage (ES) systems to simultaneously provide stacked benefits for the distribution system. In this paper, ES is used to provide the $\mathrm{N}-1$ contingency requirement as a primary application. During normal operating conditions, ES is used for multiple secondary applications, including voltage management and frequency regulation. The framework proposed in this paper is generic and can be easily adapted for other feeders, with a different set of primary and secondary application scenarios.

The second paper [2] develops an integrated multi-time-scale simulation tool for analyzing the renewable energy integration in distribution circuits. The proposed tool includes three circuit equipment models for the simulations in three different time scales, which are steady-state, electromechanical transient, and electromagnetic transient models. The proposed tool can switch from one single-time-scale model to another single-time-scale model when the power system phenomena with different time scales occur. Therefore, this tool is useful for performing a long-term simulation involving the power system phenomena spreading across time scales.

The third paper [3] proposes a technique to visualize the results obtained from the quasi-static time-series simulations of large distribution circuits. The proposed technique uses the probability density evolution to visualize the distribution of electrical variables, such as, voltages along distribution feeders and show the evolution of circuit variables over time. One of the applications of the proposed technique is to help visualize the behavior of new devices in the power systems.

The fourth paper [4] describes the historical developments of tidal energy and presents the recent advances in tidal lagoon technology. The mechanism of tide generation and the principles of tidal lagoon operation are presented. In addition, the paper also provides the characteristics of tidal power generation and discusses the opportunities, challenges, and solutions for integrating tidal lagoon power plants into the UK power system.

The fifth paper [5] investigates the impacts of renewable energy integration in the Romanian power system. This paper studies the power system in the Dobrogea area, which has the highest 
penetration of renewable energy sources. The impacts of renewable energy analyzed in this paper include the balance of power generation and consumption, power system reserve, overloading of the power system equipment, and transient stability.

The last paper [6] compares two voltage control methods, which are the traditional voltage control using capacitor banks and load tap changers (LTCs) and the new power electronics voltage control using smart inverters. The comparison of these two methods is considered from the perspective of mitigating the impacts of photovoltaics (PV) on distribution system voltages. The impacts of PV considered in this paper are the PV hosting capacity, overvoltage violations, reactive power demand at the substation, and the number of capacitor bank and LTC switching.

Conflicts of Interest: The authors declare no conflicts of interest.

\section{References}

1. Dubey, A.; Chirapongsananurak, P.; Santoso, S. A Framework for Stacked-Benefit Analysis of Distribution-Level Energy Storage Deployment. Inventions 2017, 2, 6. [CrossRef]

2. Chirapongsananurak, P.; Santoso, S. Multi-Time-Scale Simulation Tool for Renewable Energy Integration Analysis in Distribution Circuits. Inventions 2017, 2, 7. [CrossRef]

3. Hernandez, M.; Ramos, G.; Padullaparti, H.V.; Santoso, S. Statistical Inference for Visualization of Large Utility Power Distribution Systems. Inventions 2017, 2, 11. [CrossRef]

4. Todeschini, G. Review of Tidal Lagoon Technology and Opportunities for Integration within the UK Energy System. Inventions 2017, 2, 14. [CrossRef]

5. Balaban, G.; Lazaroiu, G.C.; Dumbrava, V.; Sima, C.A. Analysing Renewable Energy Source Impacts on Power System National Network Code. Inventions 2017, 2, 23. [CrossRef]

6. Dubey, A. Impacts of Voltage Control Methods on Distribution Circuit's Photovoltaic (PV) Integration Limits. Inventions 2017, 2, 28. [CrossRef]

(C) 2018 by the authors. Licensee MDPI, Basel, Switzerland. This article is an open access article distributed under the terms and conditions of the Creative Commons Attribution (CC BY) license (http:// creativecommons.org/licenses/by/4.0/). 